\title{
Erratum to: Dynamic modelling of the potential habitat loss of endangered species: the case of the Canarian houbara bustard (Chlamydotis undulata fuertaventurae)
}

Isabel Banos-González ${ }^{1,2}$ - C. Terrer ${ }^{3}$ J. Martínez-Fernández ${ }^{4}$.

M. A. Esteve-Selma ${ }^{1} \cdot$ L. M. Carrascal ${ }^{5}$

Published online: 18 October 2016

(C) Springer-Verlag Berlin Heidelberg 2016

Erratum to: European Journal of Wildlife Research 62(3):

263-275

DOI 10.1007/s10344-016-0997-x

The original article contains a mistake. The correct trinominal name of the subspecies Canarian houbara bustard is Chlamydotis undulata fuertaventurae.

The online version of the original article can be found at http://dx.doi.org/10.1007/s10344-016-0997-x.

\section{Isabel Banos-González}

ibbg1@um.es

1 Department of Ecology and Hydrology, University of Murcia, Campus de Espinardo, 30100 Murcia, Spain

2 Department of Geoscience, University of Fribourg, 4, Chemin du Musée, 1700 Fribourg, Switzerland

3 Department of Life Sciences, Imperial College London Silwood Park, Ascot SL5 7PY, UK

4 New Water Culture Foundation, C/ Pedro Cerbuna, $12,4^{\circ} \mathrm{D}$, 50009 Zaragoza, Spain

5 Department of Biogeography and Global Change, Museo Nacional de Ciencias Naturales, CSIC, C/José Gutiérrez Abascal 2,

28006 Madrid, Spain 